\title{
Post-Mortem Neurochemical Changes in Alzheimer's Disease Compared With Normal Ageing
}

\author{
M. Rossor and C.Q. Mountjoy
}

\begin{abstract}
Selective neuronal degeneration with concomitant changes in neurotransmitter systems are features of both normal ageing and Alzheimer's disease. There are, however, important neurochemical differences in cerebral cortex. Choline acetyltransferase declines with age in frontal cortex in contrast to the prominent change in the temporal cortex in Alzheimer's disease. The loss of somatostatin, and the recently reported reciprocal change in corticotropin-releasing factor and receptors are not seen with ageing. However, age itself may have an important influence on the neurochemical deficits in Alzheimer's disease which are restricted in the older patients. The problems of post-mortem studies in the analysis of ageing and possible approaches to this are discussed.
\end{abstract}

RÉSUMÉ: Comparaison des modifications neurochimiques post mortem dans la maladie d'Alzheimer et le vieillissement. Une dégénérescence neuronale sélective accompagnée de changements dans les systèmes de médiateurs chimiques sont des manifestations du viellissement normal comme de la maladie d'Alzheimer. Il existe cependant des différences neurochimiques importantes au niveau du cortex cérébral. La choline acétyltransférase diminue avec l'âge dans le cortex frontal contrairement au changement marqué qui se produit dans le cortex temporal dans la maladie d'Alzheimer. Dans le vieillissement on n'observe pas de perte de la somatostatine ou de changement réciproque du facteur de libération de la corticotropine et des récepteurs tel que rapporté dernièrement. Cependant, l'âge en lui-même peut exercer une influence importante sur les déficits neurochimiques de la maladie d'Alzheimer, cette influence étant limitée aux patients plus âgés. Nous discutons des problèmes relatifs aux études post mortem dans l'analyse du vieillissement et nous discutons des façons possibles d'aborder ces problèmes.

Can. J. Neurol. Sci. 1986; 13:499-502

Senescence, defined here as the decline in function after maturity, is normally accompanied by cell loss. Within the central nervous system (CNS), however, the cell loss may be selective, for example certain brain stem nuclei are spared.' Selective neuronal loss is also a characteristic of the CNS degenerative diseases or abiotrophies ${ }^{2}$ and this raises the question of the relationship between such diseases as Huntington's, Parkinson's and Alzheimer's disease, and the normal ageing process. This question is particularly pertinent to Alzheimer's disease, in which the additional histological features of senile plaques and neurofibrillary tangles are found to a limited degree in healthy old age. Comparison of cell losses and associated neurochemical deficits between Alzheimer's disease and normal ageing cannot elucidate the underlying mechanisms, but may provide useful clues to further research.

\section{Neurotransmitter Systems in Normal Ageing}

Data on neurotransmitter systems in human ageing are predominantly based upon post-mortem studies, many of which were designed to address different questions, with the result that the age range is often skewed. Caution must therefore be exercised in extrapolating the observed changes to the total life span, since these may not be uniform, but occur predominantly at the extremes of life. An example is the reduction in activity of tyrosine hydroxylase, the biosynthetic marker enzyme of catecholamine neurons, which follows a reciprocal plot with predominant loss in the first ten to twenty years with stable activity after that, ie: the change relates more to maturation than to senescence. ${ }^{3}$ The reduction in GABA concentrations on the other hand may occur predominantly after the seventh decade, a change clearly related to senescence. ${ }^{4}$

Post-mortem neurochemical analysis is beset by a number of problems which can result in spurious interpretation (for reviews see references 5 and 6 ). One of the most important in relation to ageing studies is the effect of tissue loss. If tissue is lost uniformally, then concentrations of chemical markers, expressed as units per gram of tissue or per gram of protein may remain unchanged, despite actual loss. To overcome this problem in a study of Alzheimer's disease, Bowen et $\mathrm{al}^{7}$ examined the whole temporal lobe to assess the total losses of chemical markers in comparison with controls. Such an approach avoids the problem of shrinkage when comparing a disease group with controls, but it does not provide information on the loss that may occur in an individual with ageing. One approach is to utilise the brain

From the Department of Neurology, St. Mary's Hospital, London, England and the National Hospital for Nervous Diseases, London, England and from St. Andrew`s Hospital, Northampton and the Department of Psychiatry, Cambridge, England

Reprint requests to: M. Rossor, Department of Neurology. St. Mary's Hospital, Praed Street, London, UK W2 INY 


\begin{tabular}{lll}
\hline Table 1: Neurochemical Changes in Cerebral Cortex in Ageing and Alzheimer's Disease & \\
\hline \hline $\begin{array}{l}\text { Neurochemical } \\
\text { Marker }\end{array}$ & Ageing & Alzheimer \\
\hline ChAT & Reduced frontal cortex & Widespread reduction, especially temporal cortex \\
MUSCARINIC RECEPTORS & Reduced or unchanged & Reduced except for presynaptic $\mathbf{M}_{2}$ receptors \\
NICOTINIC RECEPTORS & Unchanged & Reduced \\
NORADRENALINE & Slight reduction & Reduced in younger cases \\
DOPAMINE & Limited data & No change \\
SEROTONIN & Slight reduction/no change & Reduced \\
GABA & Reduced frontal cortex & Reduced temporal cortex, especially younger cases \\
SOMATOSTATIN & No change & Reduced \\
SOMATOSTATIN & & Reduced \\
RECEPTORS & No change & Reduced \\
CRF & No change & Increased \\
CRF RECEPTORS & No change & \\
\hline
\end{tabular}

Data derived from references $10-17$

volume to cranial capacity ratio. ${ }^{8}$ The skull volume, which is measured using a balloon, is constant throughout life, and as long as care is exercised in the choice of controls to exclude brain swelling, then the ratio can provide information on atrophic changes in that individual. ${ }^{8} \mathrm{U}$ sing this technique we have been able to confirm that this ratio begins to decline in the seventh decade, and found that total GABA in the brain follows a similar pattern. Volume measurement of easily dissected individual structures together with total brain volume and measurements may prove to be a useful adjunct. ${ }^{9}$

The available data indicate that the general trend with ageing is towards lowered concentration of chemical markers, although this is by no means uniform. Table 1 compares the changes in cerebral cortex in old age and Alzheimer's disease. A cholinergic abnormality, which is an important feature of Alzheimer's disease, has also been postulated to underly the memory impairment of old age ${ }^{10}$ although changes with age are modest. A reduction in muscarinic cholinergic receptors with age has been reported but this has not been a consistent finding. ${ }^{10}$ Nicotinic receptors do not show any significant age-related decrease. ${ }^{17}$ Changes in choline acetyltranserase (ChAT) are also minor. An early report suggested a dramatic loss after the age of $80,{ }^{18}$ but this has not been confirmed in other studies. ${ }^{10.14}$

In our own series of elderly controls nineteen areas of cere. bral cortex were examined, and only Brodmann areas eight and ten of the frontal cortex showed a significant decline with age. ${ }^{14}$ The number of cholinergic neurons in the nucleus basalis are reported to decline with age but a prominent loss occurs early in life. ${ }^{19} \mathrm{~A}$ recent report suggests that in mice the number of cholinergic neurons is stable but the size of cells is reduced. ${ }^{20}$ Amine systems also show some decline with age, and reduced noradrenaline concentrations reflect the loss of locus coeruleus neurons.'

In contrast to the ascending systems the status of cortical transmitters has been less well studied. Glutamate, a major cortical transmitter, cannot be measured reliably in post-mortem tissue due to the difficulty of distinguishing the metabolic and neurotransmitter pools. The concentration of GABA, which may be a more accurate reflection of the status of GABA neurons than glutamic acid decarboxylase, has been shown to decline with age, particularly in the frontal cortex. ${ }^{14.16}$ This decline may occur predominantly after the seventh decade. ${ }^{4}$
Cortical peptide changes with age have not been studied systematically in human ageing, but in general appear stable. Somatostatin does not change with age, ${ }^{12.15}$ an interesting observation in view of the reduction in GABA concentration, since recent primate studies suggest that somatostatin co-exists with GABA in cortical neurons. ${ }^{21}$

\section{Neurochemical Changes in Alzheimer's Disease}

The cholinergic deficit in Alzheimer's disease can now be seen as part of a wider spectrum of neurochemical abnormalities but of the changes in ascending projections to cortex the cholinergic remains the most consistent, with losses of up to $80 \%$ of cortical ChAT activity. This is most marked in the temporal lobe, and includes the neocortex, hippocampus and amygdala. These losses are greater than the small changes seen in ageing, and contrast in being maximal in the temporal as opposed to the frontal cortex. The changes in catecholamine systems in Alzheimer's disease are also in the same direction as that seen in normal ageing, but are quantitatively more severe.

The changes in cortical neurotransmitters are difficult to interpret, as indeed they are in normal ageing. Little information is available on glutatamate, and the status of GABA neurons has also been difficult to assess. Glutamic acid decarboxylase activity is variable reduced, but this is probably due to an agonal effect (for review see reference 22). Concentrations of GABA itself are reduced, particularly in the temporal cortex by about $30 \% .^{14.23}$ The change in GABA concentration is also found predominantly in younger cases (see below). Many neuropeptides have been measured in the cerebral cortex, but the only two to show consistent changes are somatostatin and corticotropin releasing factor (CRF). ${ }^{11.12,13.15 .24}$ Both of these are reduced throughout the cortex, but predominantly in the temporal cortex in the case of somatostatin, and this contrasts clearly with the stability in normal old age. ${ }^{15} \mathrm{CRF}$ and receptors are also unaltered in normal ageing and this contrasts with the reciprocal increase in receptors in Alzheimer's disease. ${ }^{13}$

\section{The Influence of Age on Neurochemical Changes in Alzheimer's Disease}

Paradoxically the clinical, histological and neurochemical features in Alzheimer's disease have been found to be more severe in younger patients. Bowen et al, ${ }^{25}$ originally reported 

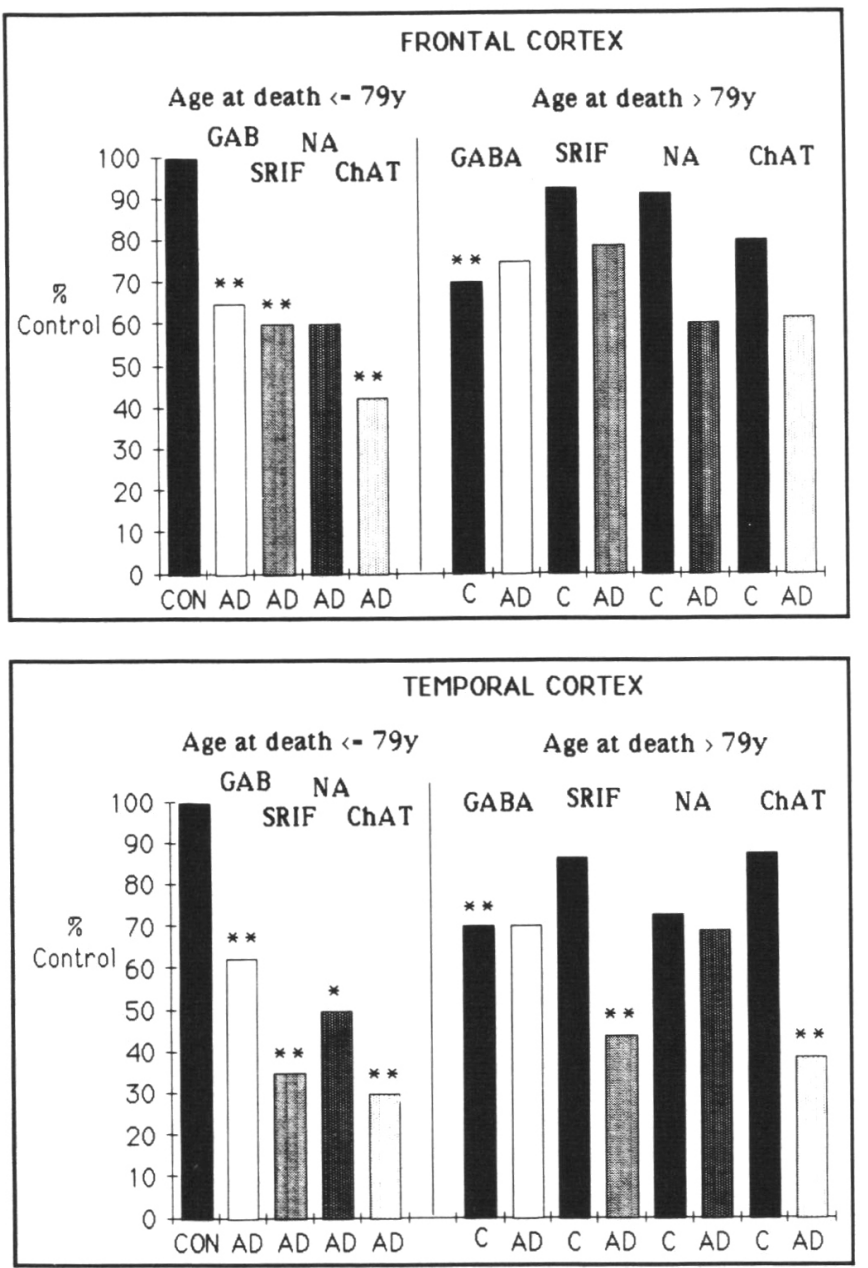

lower ChAT activity in patients dying below the age of 80 , when compared with older patients. We have explored further this paradoxical interaction by dividing our cases on the basis of the median age of our series, 79 years. This was found to distinguish two groups of Alzheimer cases with a differing pattern of ChAT deficit. ${ }^{14}$ Not only was the enzyme reduction less severe in the older (greater than 79 years) cases but it was also found to spare the frontal lobe in this older group. This age distinction was then used in a larger series, which included measurement of noradrenalin, GABA and somatostatin. ${ }^{15}$ Figure 1 summarises the data from this study. Analysis shows that the changes in GABA and noradrenalin were confined to younger cases, and again confirmed the sparing of the frontal lobe in terms of the cholinergic deficit in older cases. This analysis by age also allowed a direct comparison between young Alzheimer's disease and the very old control group, and it was found that the cholinergic and somatostatin deficits still persisted. By contrast the GABA concentrations in Alzheimer's disease were indistinguishable from the very old control group.

Recently, Bondareff et $\mathrm{al}^{2}{ }^{26}$ have re-analysed the biochemical data together with histological features, which included plaque counts, tangle estimates and neuronal counts within the locus coeruleus. Discriminant function analysis confirms that age at death is an important factor in distinguishing two groups of patients with characteristic clusters of histological and biochemical features.

\section{Conclusion}

Although the direction of the change of neurochemical markers in Alzheimer's disease is the same as that for normal ageing there are important quantitative differences. The peptide changes are not seen in normal ageing and the decline in ChAT with age in normal controls is found in the frontal cortex, whereas the major change in Alzheimer's disease is in the temporal cortex, and there may be sparing of the frontal cortex in older cases. Moreover comparison with a very old control group still shows substantial deficit. It might be argued that extrapolation of the normal ageing curve beyond 100 years might then show changes indistinguishable from those of Alzheimer's disease, but unless the underlying molecular process of normal ageing is understood then to state that Alzheimer's disease is an accelerated form of ageing adds little to our understanding. It is likely that to focus on the distinction from normal ageing will be useful, and may be important in the management and assessment of patients. The discriminant function analysis suggests that the age of the patient may predict the likely underlying neurochemical deficits, which in turn might direct attempts at replacement therapy.

\section{REFERENCES}

1. Tomlinson BE. The structural and Quantitative Aspects of the Dementias. In: Biochemistry of Dementia. Roberts PJ, ed. John Wiley and Sons Ltd (1980). pp 15-52.

2. Gowers WR. A lecture on abiotrophy. Lancet 1982; 1: 1003-1007.

3. McGeer PL, McGeer EG, Suzuki JS. Ageing and extrapyramidal function. Arch Neurol 34: 33-35.

4. Rossor MN and Mountjoy CQ. Unpublished observation.

5. Perry EK and Perry RH. Human Brain Neurochemistry - some post-mortem problems. Life Sci 1983; 33: 1733-1743.

6. Rossor MN. Post-mortem neurochemistry of human brain. Progress in Brain Res 1986; 65: 167-175.

7. Bowen DM, Smith CB, White P, et al. Neurotransmitter-related enzymes and indices of hypoxia in senile dementia and other abiotrophies. Brain 1976; 99: 459-496.

8. Davis PJM and Wright EA. A new method for measuring cranial cavity volume and its application to the assessment of cerebral atrophy at autopsy. Neuropath appl Neurobiol 1977; 3: 341-358.

9. Hubbard BM and Anderson JM. A Quantitative study of cerebral atrophy in old age and senile dementia. J Neurol Sci 1981; 50: 135-145.

10. Bartus RT, Dean RL, Beer B, et al. The cholinergic hypothesis of geriatric memory dysfunction. Science, 1982; $217: 408-417$.

11. Beal MF, Mazurek MF, Tran VT, et al. Reduced numbers of somatostatin receptors in the cerebral cortex in Alzheimer's disease. Science 1985; 229: 289-291.

12. Davies P, Katzman R and Terry RD. Reduced somatostatin-like immunoreactivity in cerebral cortex from cases of Alzheimer's disease and Alzheimer senile dementia. Nature 1980; 288: 279-280.

13. De Souza EB, Whitehouse PJ, Kuhar MJ, et al. Alzheimer's disease: reciprocal changes in corticotropin-releasing factor (CRF)-like immunoreactivity and CRF receptors in cerebral cortex. Nature 1986; 319: 593-595.

14. Rossor MN, Garrett NJ, Johnson AL, et al. A post-mortem study of the cholinergic and GABA systems in senile dementia. Brain 1982; 105: 313-330.

15. Rossor MN, Iversen LL, Reynolds GP, et al. Neurochemical characteristics of early and late onset types of Alzheimer's disease. $\mathrm{Br}$ Med J 1984; 288: 961-964.

16. Spokes EGS, Garrett NJ, Rossor MN, et al. Distribution of GABA in post-mortem brain tissue from control, psychotic and Huntington's chorea subjects. J Neurol Sci 1980; 48: 303-313.

17. Whitehouse PJ, Martino AM, Antuono PG, et al. Nicotinic acetylcholine binding sites in Alzheimer's disease. Brain Res 1986; 371: 146-151. 
18. Davies P. Neurotransmitter related enzymes in senile dementia of the Alzheimer type. Brain Res 1979; 171: 319-327.

19. McGeer PL, McGeer EG, Suzuki J, et al. Ageing, Alzheimer's disease and the cholinergic system of the basal forebrain. Neurology 1984; 34: 741-745.

20. Coleman PD, Hornberger JC, Binell SJ. Stability of number but not size of acetylcholinesterase-positive neurons of basal forebrain in C57B1/6 mice between 7 to 53 months. Neurosci Lett 1985, Suppl 22, 558 .

21. Hendry SHC, Jones EG, De Felipe J, et al. Neuropeptide-containing neurons of the cerebral cortex are also GABAergic. Proc Nat Acad Sci USA 1984; 81: 6526-6530.

22. Rossor M, Iversen LL. Non-cholinergic neurotransmitter abnormalities in Alzheimer's disease. Brit Med Bull 1986; 42(1): 70-74.
23. Ellison DW, Beal MF, Mazurek MF, et al. A post-mortem study of amino acid neurotransmitters in Alzheimer's disease. Ann Neurol 1986 (in press).

24. Bissette G, Reynolds GP, Kilts CD, et al. Corticotropin-releasing factor-like immunoreactivity in senile dementia of the Alzheimer type. J A M A 1985; 254: 3067-3069.

25. Bowen DM, Spillane JA, Curzon G, et al. Accelerated ageing or selective neuronal loss as an important cause of dementia. Lancet 1979; i: 11-14.

26. Bondareff W, Mountjoy CQ, Roth M, et al. Histopathological heterogeneity in Alzheimer's disease: evidence for subtypes. Arch Gen Psych (in press). 